\title{
Effect of Oxygen Content Upon the Microstructural and Mechanical Properties of Type 316L Austenitic Stainless Steel Manufactured by Hot Isostatic Pressing
}

\begin{abstract}
ADAM J. COOPER, NORMAN I. COOPER, JEAN DHERS, and ANDREW H. SHERRY
Although hot isostatic pressing (HIP) has been shown to demonstrate significant advances over more conventional manufacture routes, it is important to appreciate and quantify the detrimental effects of oxygen involvement during the HIP manufacture process on the microstructural and material properties of the resulting component. This paper quantifies the effects of oxygen content on the microstructure and Charpy impact properties of HIP'd austenitic stainless steel, through combination of detailed metallographic examination and mechanical testing on HIP'd Type 316L steel containing different concentrations (100 to $190 \mathrm{ppm}$ ) of oxygen. Micron-scale pores were visible in the microstructure of the HIP'd materials postmetallographic preparation, which result from the removal of nonmetallic oxide inclusions during metallographic preparation. The area fraction of the resulting pores is shown to correlate with the oxygen concentration which influences the Charpy impact toughness over the temperature range of $77 \mathrm{~K}$ to $573 \mathrm{~K}\left(-196{ }^{\circ} \mathrm{C}\right.$ to $\left.300{ }^{\circ} \mathrm{C}\right)$, and demonstrates the influence of oxygen involved during the HIP manufacture process on Charpy toughness. The same test procedures and microstructural analyses were performed on commercially available forged 316L. This showed comparatively fewer inclusions and exhibited higher Charpy impact toughness over the tested temperature range.
\end{abstract}

DOI: $10.1007 / \mathrm{s} 11661-016-3612-6$

(C) The Author(s) 2016. This article is published with open access at Springerlink.com

\section{INTRODUCTION}

HoT isostatic pressing (HIP) is the process by which metal components are fabricated from the consolidation of a metal powder of required chemistry, to bulk material via the application of high temperature and isostatically controlled pressure, under an inert atmosphere. ${ }^{[1-3]}$ HIP permits several advantages over conventional forging and casting procedures, the most significant being the possibility for near-net shape manufacture. ${ }^{[2-6]}$ Because consolidation occurs in a prefabricated vessel, the vessel may be developed to allow HIP of a component with a relatively complex shape and geometry, of which might only be possible via forging through machining or additional welded joints. This advantage can result in significantly reduced associated machining and welding costs, less wasted material due to fewer machining stages, increased design

ADAM J. COOPER, Postdoctoral Research Associate, is with the School of Materials, University of Manchester, Oxford Road, M13 9PL, U.K. Contact e-mail: adam.cooper@manchester.ac.uk NORMAN I. COOPER, Head of Materials Technology, is with BAE Systems, Bridge Road, Barrow-in-Furness, LA14 1AF, U.K JEAN DHERS, Manager of Areva Research and Development, is with AREVA, Lyon, France. ANDREW H. SHERRY, Chief Scientist, is with the National Nuclear Laboratory, Birchwood Park, Warrington, WA3 6AE, U.K.

Manuscript submitted November 26, 2015.

Article published online June 22, 2016 freedom, as well as easier inspection via nondestructive examination techniques due to HIP's tendency to produce components with much smaller grain sizes than chemically equivalent forged materials. Furthermore, Hot Isostatically Pressed (HIP'd) materials typically display increased yield strengths, UTS, and enhanced ductility over "chemically equivalent" forged counterparts, which is generally attributed to HIP's smaller grain size and isotropic grain structure, exhibiting no grain directionality like that of rolled plates.

However, although HIP is a relatively popular manufacture route toward components employed in oil and gas, as well as the aerospace industry, the more extreme safety concerns associated with the nuclear sector require much greater insight into the potential issues regarding HIP, and as such, HIP is yet to launch as a serious rival to forging and casting for the manufacture of components used within integral parts of a nuclear reactor, specifically those which are subjected to irradiation damage. Before it is introduced, components fabricated by HIP must stand up to all of the basic standards and code cases set by conventional forged components, in order to justify implementation of a different manufacture route.

One particular issue surrounding HIP manufacture of austenitic stainless steel concerns the concentrations of oxygen that remain in the austenite matrix after HIP and ultimately have a detrimental effect upon the material's Charpy impact toughness. ${ }^{[7-9]}$ Although this is a 
well-known metallurgical phenomenon which is not restricted to austenitic materials, as shown by the reported relationship between oxygen concentrations in weld metal and impact toughness of the resulting weld, ${ }^{[10,11]}$ HIP manufacturers typically achieve a minimum oxygen levels over an order of magnitude greater than those typically found in forgings and castings, largely due to the challenges associated with reducing the oxygen levels further, since powder surface oxidation, one of the main mechanisms by which oxygen interferes, can arise during powder handling and storage.

Although the effects of oxygen on microstructural and mechanical properties are appreciated, the role in which oxygen operates to lower impact toughness is still debated. It is well known that powder surface oxidation can reduce the impact toughness of the final HIP'd material ${ }^{[8,12]}$ and it is believed that excessive surface oxidation of the powder particles prior to HIP can prevent complete interaction between neighboring particles, which can result in internal porosity in the HIP'd material. ${ }^{[8,9,13]}$ However, questions remain on how the oxygen manifests itself in the matrix of the HIP'd material, either in solid solution, in the form of nonmetallic inclusions, or as microporosity, the mechanism by which oxygen operates in the fracture mechanism, and if there is a maximum oxygen concentration in the HIP'd material (and powder) that ensures the impact toughness is comparable to that of "chemically equivalent" forged/cast material. In addition to this, it is sometimes unclear whether quoted oxygen concentrations are those of (a) the initial powder specification, (b) the actual measured concentration in the powder, of which transportation and handling can affect significantly, or (c) the final HIP'd material.

In previous work, ${ }^{[14]}$ the authors showed that the Charpy impact toughness of HIP'd 304L and 316L was consistently lower than that of chemically equivalent forged 304L stainless steel, the only difference between the materials being the grain size and a substantially higher concentration of oxygen in the HIP'd steel than in the forged ( $c a .120 \mathrm{ppm} c f .15 \mathrm{ppm}$, respectively). This study expands on the previous work by testing HIP 316L austenitic stainless steel containing various levels of oxygen in the bulk metal, and shows that the level of oxygen can be directly related to the degree of observable pores in the microstructure, which result from nonmetallic oxide inclusions being dislodged from the material during surface polishing. Furthermore, it is shown that increasing the level of oxygen in the HIP material is detrimental to the material impact toughness and ductility.

\section{EXPERIMENTAL}

Four heats of HIP'd 316L (A, B, D, E) were obtained from the Electrical Power Research Institute (EPRI, USA) containing final-material oxygen concentrations of 100,100, 145, and 190 ppm, respectively. An additional heat of HIP'd 316L (C) was obtained from AREVA, France, which contained a final oxygen concentration of $120 \mathrm{ppm}$. The materials have been listed alphabetically in order of increasing oxygen content. All the materials' elemental compositions (wt pct) are tabulated in Table I. Grain size measurements were conducted in accordance with ASTM E112-96 ${ }^{[15]}$ and the results are tabulated in Table I. For the HIP materials studied, independent batches of $316 \mathrm{~L}$ stainless steel powders were heated to $1423 \mathrm{~K}\left(1150{ }^{\circ} \mathrm{C}\right)$ under 1050 bar pressure for a total period of 3.5 hours. All HIP'd materials were solution annealed and quenched. Forged $316 \mathrm{~L}$ was subjected to the same heat treatment procedure as the HIP materials.

Charpy V-notch specimens were machined in accordance with ASTM A370 recommended ${ }^{[16]}$ dimensions $(10 \times 10 \times 55 \mathrm{~mm})$. Forged material Charpy specimens were extracted from a forged plate and machined with $\mathrm{L}-\mathrm{T}$ orientation, where $\mathrm{L}=$ longitudinal direction (rolling direction) and $\mathrm{T}=$ transverse direction. HIP material Charpy specimens were machined from blocks, and the isotopic nature of the grain structure means that the orientation of HIP specimens is less important. Charpy impact testing was performed using an instrumented Charpy testing rig (impact velocity $c a .5 .23 \mathrm{~m} \mathrm{~s}^{-1}$ ). Samples for subzero testing were cooled to $173 \mathrm{~K}$ $\left(-100^{\circ} \mathrm{C}\right)$ using a liquid nitrogen-controlled fridge, or cooled to $73 \mathrm{~K}\left(-196^{\circ} \mathrm{C}\right)$ by submerging in liquid nitrogen for $c a$. 20 minutes prior to testing. Samples for elevated temperature testing were heated to $473 \mathrm{~K}$ $\left(200{ }^{\circ} \mathrm{C}\right)$ or $573 \mathrm{~K}\left(300^{\circ} \mathrm{C}\right)$ by placing in an oven for 30 minutes.

Specimens prepared for metallurgical analysis were sectioned, mounted, ground, and polished in accordance with the recommended procedures in ASTM Practice E3-01. ${ }^{[17]}$ Electropolishing was performed on specimens prepolished to a $1 / 4 \mu \mathrm{m}$ finish, using a voltage of $20 \mathrm{~V}$ for 25 seconds, in an electrolyte solution consisting of 5 pet perchloric acid in 95 pct methanol, at a temperature of $233 \mathrm{~K}\left(-40^{\circ} \mathrm{C}\right)$.

Electron microscopy was performed using an FEI Quanta 650 ESEM and an FEI Sirion SEM, both equipped with field emission guns and electron back-scattered diffraction (EBSD) detectors, and a Hitachi S-3700 scanning electron microscope equipped with Oxford Instruments INCA X-ACT energy dispersive spectroscopy for semiquantitative chemical analysis. The SEM was performed under vacuum using an $8 \mathrm{kV}$ accelerating voltage and a spot size of $4.0 \mathrm{~nm}$, at a working distance (WD) of approximately $15 \mathrm{~mm}$.

Statistical analysis of microporosity was performed on ca. 1000 pores (per specimen) located in random locations on polished sections of $316 \mathrm{~L}$. Surfaces were repolished several times to reveal different analysis planes. SEM images of pores were analyzed using Image J particle analysis software, and the gray scale threshold adjusted such that particle areas could be measured, from which area fractions were calculated.

\section{RESULTS}

Figure 1(a) shows Charpy impact toughness data obtained for specimens extracted from the five different heats of HIP'd material, which had measured oxygen 
Table I. Elemental Compositions of Tested Materials

\begin{tabular}{|c|c|c|c|c|c|c|c|c|c|}
\hline & & \multicolumn{8}{|c|}{ Composition (Weight Percent) } \\
\hline & & $\mathrm{C}$ & Mn & $\mathrm{Si}$ & $\mathrm{Ni}$ & $\mathrm{Cr}$ & Mo & $\mathrm{N}(\mathrm{ppm})$ & $\mathrm{O}(\mathrm{ppm})$ \\
\hline Spec. (weight percent) & grain size & $<0.030$ & $<2.00$ & $<1.0$ & 10.0 to 14.0 & 16.0 to 18.0 & 2.0 to 3.0 & $<1000$ & - \\
\hline F316L & ASTM G5.0 & - & - & - & - & - & - & 880 & 23 \\
\hline HIP316L-A & ASTM G5.5 & 0.021 & 0.95 & 0.80 & 13.2 & 17.3 & 2.55 & 1000 & 100 \\
\hline HIP316L-B & ASTM G5.5 & 0.013 & 0.90 & 0.70 & 12.1 & 17.3 & 2.55 & 1400 & 100 \\
\hline HIP316L-C & ASTM G7.0 & 0.016 & 1.37 & 0.6 & 11.85 & 17.2 & 2.30 & 370 & 120 \\
\hline HIP316L-D & ASTM G7.0 & 0.013 & 1.7 & 0.5 & 12.3 & 17.6 & 2.46 & 750 & 145 \\
\hline HIP316L-E & ASTM G7.0 & 0.004 & 1.41 & 0.55 & 13.3 & 16.9 & 2.37 & 380 & 190 \\
\hline
\end{tabular}

concentrations of $100,100,120,145$, and $190 \mathrm{ppm}$, respectively. Data are also included from tests conducted by EPRI, who completed additional room temperature Charpy tests on the HIP-A, -B, and -E materials. ${ }^{[18]}$ The degree of data scatter decreased significantly with increasing oxygen content, and this could be attributed to the increased spatial probability of oxide particles playing a role on fracture with higher oxygen contents. All of the data show a steady reduction in impact toughness with decreasing temperature, which is attributed to the formation of strain-induced martensite close to the notch root during impact. ${ }^{[14]}$ Increasing levels of oxygen present in the HIP'd materials correspond to a consistently depreciated impact toughness below ambient temperature; this relationship is shown in Figure 1(b), whereas a constant decrease in toughness with decreasing temperature is observed for the HIP materials over the entire temperature range. By comparison, the impact toughness of forged $316 \mathrm{~L}$ is relatively unaffected by temperature above room temperature. Because of this, differences in impact toughness between HIP'd and forged materials are more pronounced at ambient and depreciated temperatures than at elevated temperatures. Depreciated temperature tests also exhibit an exponential decay trend, indicating that increasing the oxygen concentration in the HIP'd steels to values exceeding $200 \mathrm{ppm}$ eventually has little effect on the material properties.

Figure 2 shows the instrumented Charpy data presented as absorbed energy vs displacement curves obtained from the two most extreme temperature tests: (a) $77 \mathrm{~K}\left(-196{ }^{\circ} \mathrm{C}\right)$ and (b) $573 \mathrm{~K}\left(300{ }^{\circ} \mathrm{C}\right)$. Figure 2(a) highlights how cryogenic temperature testing is able to enhance the effects of oxygen involvement, since the reduced degree of plasticity is unable to compete with the oxygen's apparent embrittling effect.

Figures 3(a) through (d) shows the instrumented load vs displacement curves obtained from the Charpy tests, at four different test temperatures, for each material; for clarity, data corresponding to one of the $100 \mathrm{ppm}$ specimens (HIP316L-B) and the $120 \mathrm{ppm}$ specimen (HIP316L-C) have been omitted from the plots. At elevated temperature (Figure 2(a)), the load/displacement curves are relatively similar, showing comparable degrees of plastic deformation, equivalent maximum peak loads, and extent the of plateau region. At ambient temperature (Figure 2(b)), there is a significant difference in toughness between the forged $316 \mathrm{~L}$ and the HIP'd 316L specimens, through a reduction in the

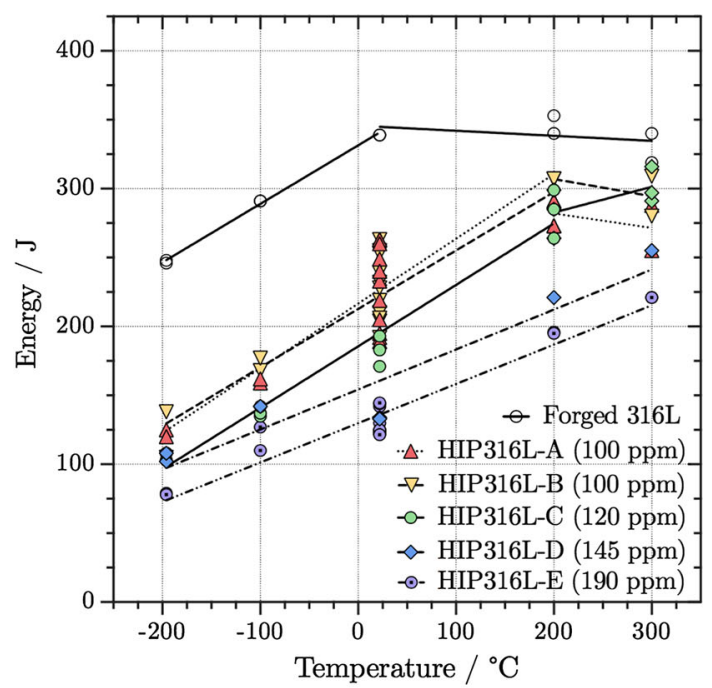

(a)

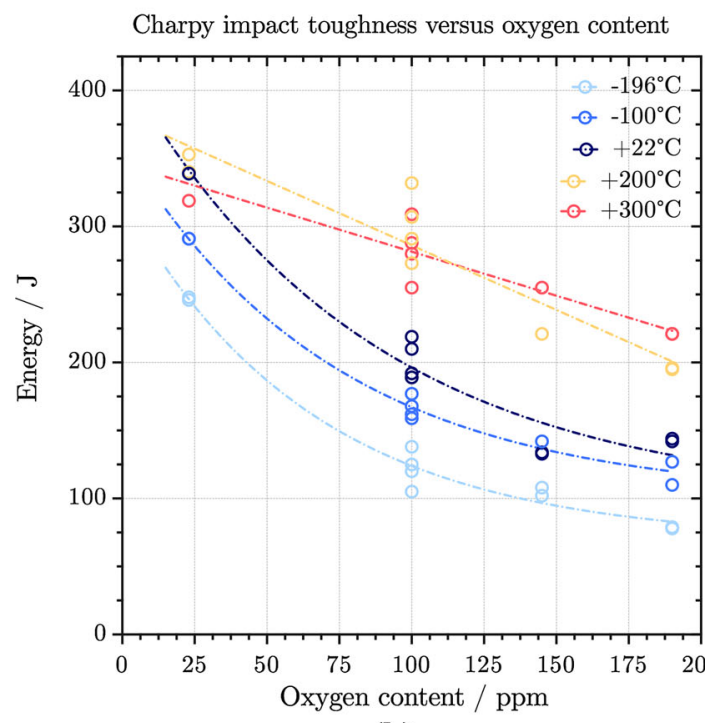

(b)

Fig. 1-Charpy impact toughness vs (a) temperature, for five heats of HIP316L with increasing oxygen content and chemically equivalent forged $316 \mathrm{~L}$ material, over a temperature range of $77 \mathrm{~K}$ to $573 \mathrm{~K}\left(-196{ }^{\circ} \mathrm{C}\right.$ to $\left.+300{ }^{\circ} \mathrm{C}\right)$, and $(b)$ oxygen content, at five different test temperatures.

degree of plastic deformation and plateau region of the HIP $316 \mathrm{~L}$ specimens. At room temperature, increasing the oxygen content from 100 to $145 \mathrm{ppm}$ has the effect 


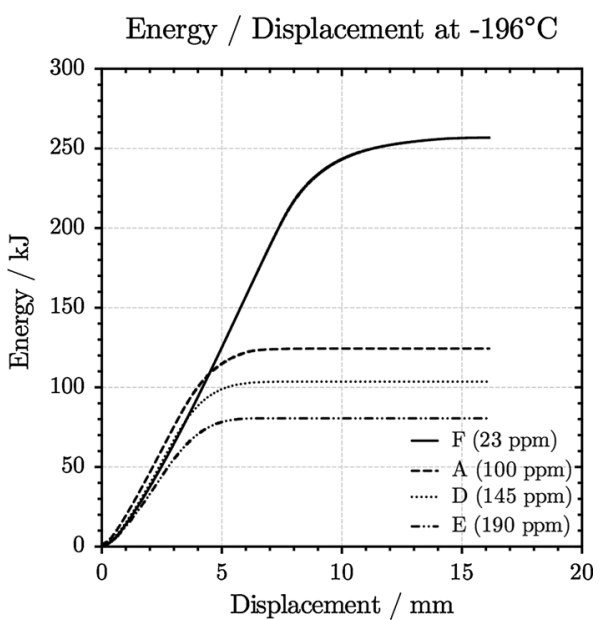

(a)

Energy / Displacement at $300^{\circ} \mathrm{C}$

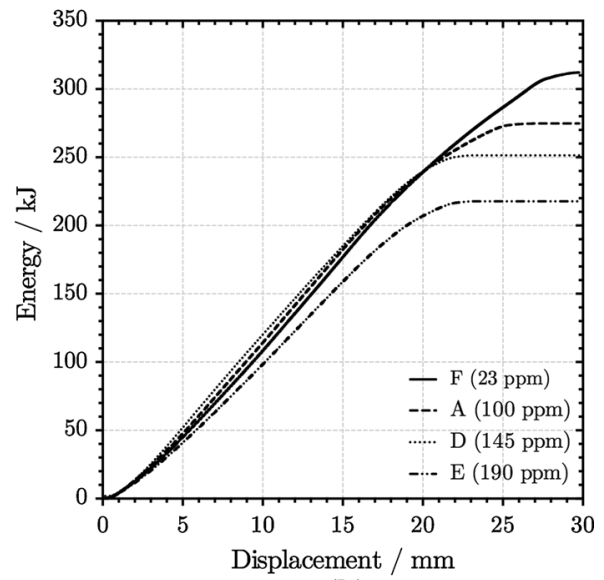

(b)

Fig. 2-Energy vs Displacement data for forged and HIP specimens at (a) $77 \mathrm{~K}\left(-196{ }^{\circ} \mathrm{C}\right)$ and $\left(\right.$ b) $573 \mathrm{~K}\left(300^{\circ} \mathrm{C}\right)$, highlighting the embrittling effect of oxygen involvement on the ductility of $316 \mathrm{~L}$ steel at cryogenic temperature.

of further reducing impact toughness in the same fashion, and a reduction in both the general yield, $F_{\mathrm{gy}}$, is not evident until the oxygen concentration is further increased to $190 \mathrm{ppm}$. However, when the test temperature is lowered to $173 \mathrm{~K}$ and $77 \mathrm{~K}\left(-100{ }^{\circ} \mathrm{C}\right.$ and $-196^{\circ} \mathrm{C}$ ), increasing the oxygen concentration in the HIP steels to $145 \mathrm{ppm}$ has a marked effect on both the total degree of plastic deformation and the $F_{\mathrm{m}}$, and eventually on general yielding when the oxygen content is as high as $190 \mathrm{ppm}$.

Figure 4 shows the Charpy specimen fracture surfaces for forged $316 \mathrm{~L}$ (a-e) and HIP316L-B (f-j) at five different temperatures. At $275 \mathrm{~K}$ and $375 \mathrm{~K}\left(200{ }^{\circ} \mathrm{C}\right.$ and $300{ }^{\circ} \mathrm{C}$ ), both HIP and forged Charpy specimens failed to fracture completely, yielding heavily plastically deformed Charpy specimens with shallow ductile crack depths and similar fracture surface morphologies. This observation coincides with the similar Charpy energies recorded for F316L and HIP316L-A and HIP316L-B.

Figure 5(a) shows a secondary electron SEM image of the as-etched HIP316L-C and highlights the presence of both nonmetallic oxide inclusions $\left(\mathrm{Cr}_{2} \mathrm{O}_{4}\right.$ and $\left.\mathrm{MnO}\right)$ as well as pores, and the chemical analyses of the seven labeled sites are tabulated in Table II. The inclusions contain between ca. 30 and 50 wt pct oxygen. This metallographic appearance was typical of all etched HIP specimens, whereas etched F316L yielded a microstructure with little in the way of inclusions and pores as shown in Figure 5(b). In order to establish whether the pores were a result of internal porosity or dislodged inclusions, various surface preparation techniques were employed. Figures 5(b) and (c) shows HIP316L-A and HIP316L-E, respectively, after mechanical polishing to a $1 / 4 \mu \mathrm{m}$ finish to compare the metallography of the minimum and maximum oxygen concentration materials, and only micron-scale pores were evident in all microstructures. Very few inclusions were observed in the microstructure after metallographic preparation by mechanical polishing, and EDS analysis of the pores revealed a chemical makeup matching that of the parent material. The number of pores was found to be related to the total concentration of oxygen in the bulk HIP'd specimens, as highlighted when comparing Figure 5(b) and (c). It was believed that mechanical polishing has the effect of dislodging matrix-bound nonmetallic inclusions, and to test this, electropolishing of the surface was employed in order to permit sufficient polishing of the surface without causing removal of inclusions; this was successful and typical electropolished surfaces are shown in Figure 5(d) and (e) of HIP316L-A and HIP316L-E, respectively, again comparing minimum and maximum oxygen concentrations. As in Figure 5(b) and (c), the quantity of inclusions is related to the total concentration of oxygen. Chemical analyses of these inclusions provided chemical compositions similar to those presented in Table II. From these data, it can be concluded that all the pores observed are most likely the result of mechanical polishing, whereby nonmetallic inclusions are dislodged from the austenite matrix leaving behind a hole on their removal. It was therefore assumed that total no. of pores $\equiv$ total no. of inclusions for subsequent quantitative analysis. Since mechanical polishing without etching or electropolishing produced specimens with minimal topographic flatness and therefore enhanced contrast between pores (previously inclusions) and bulk material, further analysis was performed on these images. Statistical analysis on the actual inclusions as revealed in the electropolished images would have been preferable to pores, but this was challenging due to the topographic nature of the electropolishing process, which produced images that were difficult to threshold for particle analysis.

Statistical analysis was performed on the pores, as detailed in Section II, and the results presented in Figure 6. Figure 6(a) shows the mean pore radii $(\mu \mathrm{m}) v s$ oxygen content and the average pore radius is consistently less than $0.3 \mu \mathrm{m}$ for the oxygen contents studied. The data indicate that the average pore radius is not affected by oxygen content. Herein, measured pore sizes are expressed as pore radii, in $\mu \mathrm{m}$, determined from sectioned metallographic planes. It is important to note that this is not a true representation of particle size, since it is a 2-dimensional simplification of a 3-dimensional feature, and the probability of sectioning a pore directly along the 
Load / Displacement at $300^{\circ} \mathrm{C}$

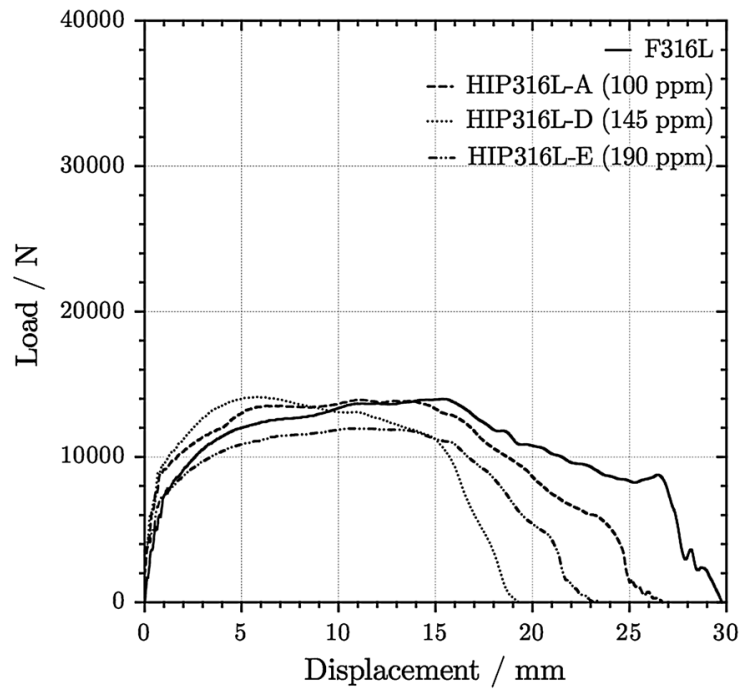

(a)

Load / Displacement at $-100^{\circ} \mathrm{C}$

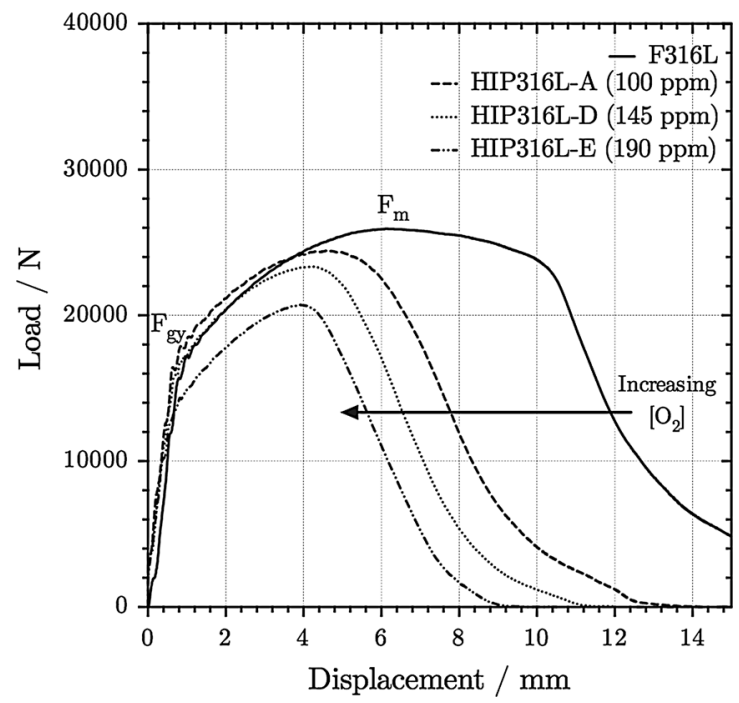

(c)
Load / Displacement at $22^{\circ} \mathrm{C}$

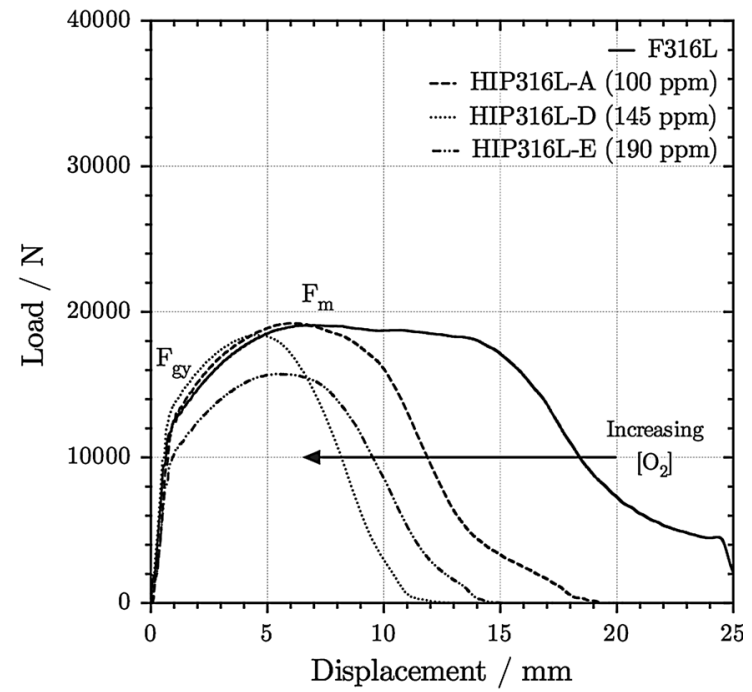

(b)

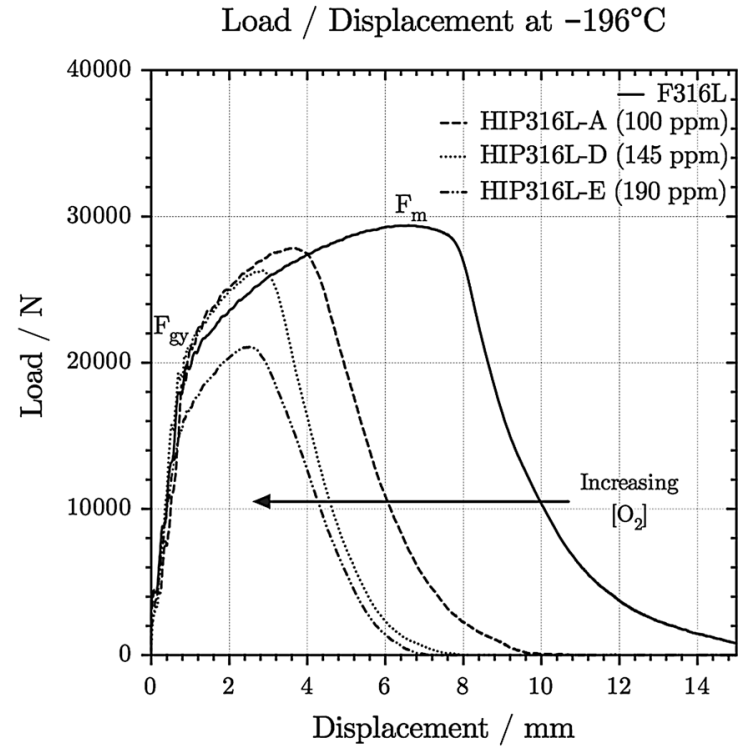

(d)

Fig. 3-Load vs displacement data for forged and HIP specimens at (a) $573 \mathrm{~K}\left(300{ }^{\circ} \mathrm{C}\right),\left(\right.$ b) $295 \mathrm{~K}\left(22{ }^{\circ} \mathrm{C}\right),(c) 173 \mathrm{~K}\left(-100{ }^{\circ} \mathrm{C}\right)$, and $(d) 77 \mathrm{~K}$ $\left(-196{ }^{\circ} \mathrm{C}\right)$, showing the effects of oxygen involvement on the material toughness.

equator is highly unlikely. As a result, the measured radii of the pores are a slight underestimation of the actual 3 -dimensional radii of the inclusions that previously accommodated these pores.

Figure 6(b) shows the relationship between the total area fraction of pores $v s$ oxygen content. Since the number of inclusions in F316L was so small in comparison to HIP specimens, F316L has been included in all subsequent datasets with corresponding pore sizes and area fractions equal to zero. For the HIP material, there is a clear linear relationship between the total pore area fraction and oxygen content, even when considering the standard deviation of the data. Three linear regression trends have been applied to the data: the first (blue, central) through the mean total area fraction values, and the second and third lines through the upper and lower limits of the standard deviation bars, respectively. By extrapolation of the linear regression trend through the upper limit of the standard deviation bars, which would be considered a more conservative assessment, the data suggest that there is a maximum threshold of $c a .30 \mathrm{ppm}$ oxygen which can be accommodated by the austenite matrix.

Finally, Figure 7 shows how the Charpy impact energy varies with increasing porosity area fraction, over the entire test temperature range. These trends are similar to those presented in Figure 1(b) due to the linear dependence of porosity area fraction on the concentration of residual oxygen remaining in the steel; however, it does indicate that the area fraction, and 

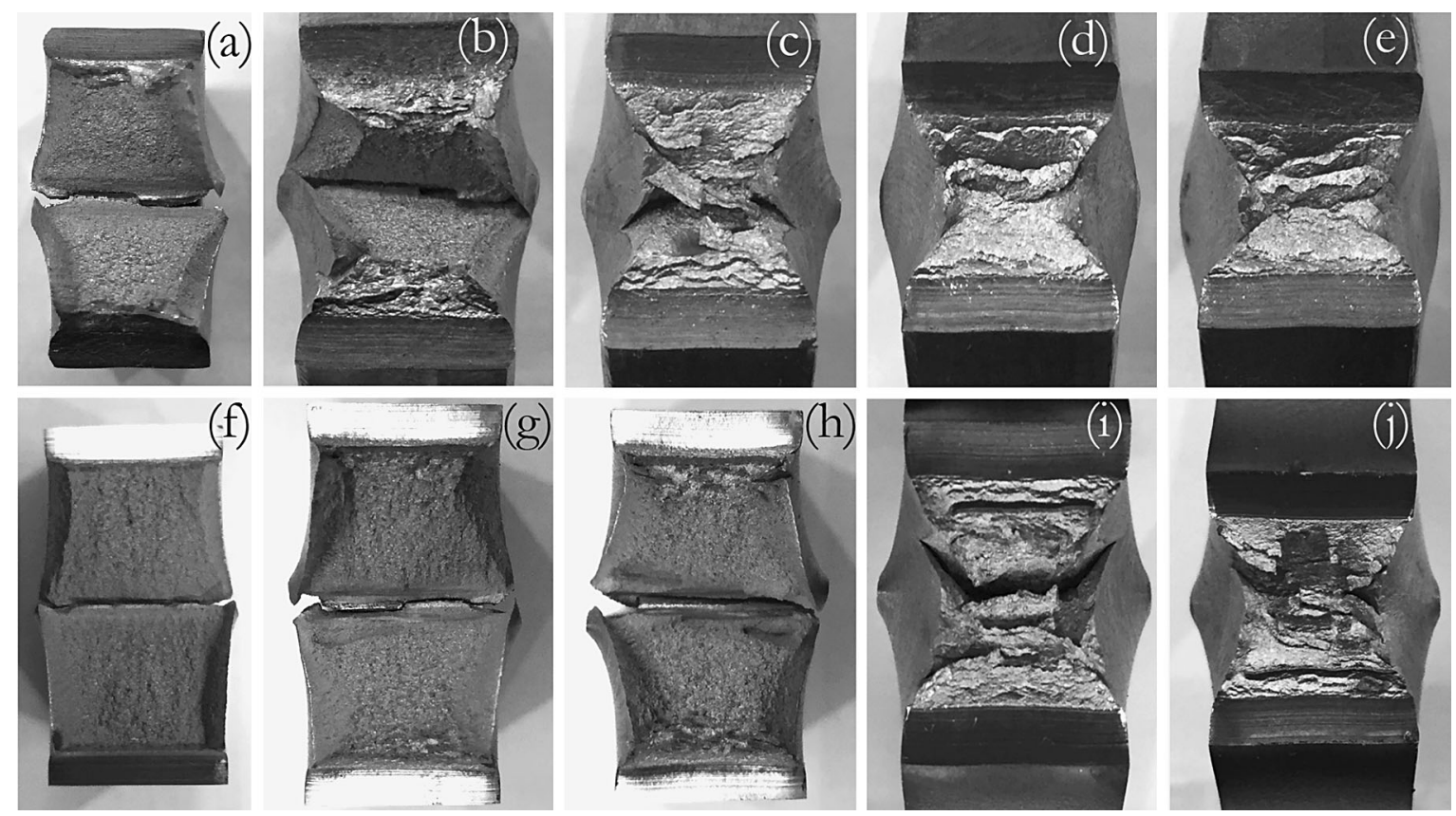

Fig. $4-$ F316L $(a-e)$ and HIP316L-B $(f-j)$ Charpy fracture surfaces after testing at $(\mathrm{a}, \mathrm{f}) 77 \mathrm{~K}\left(-196{ }^{\circ} \mathrm{C}\right),(\mathrm{b}, \mathrm{g}) 173 \mathrm{~K}\left(-100{ }^{\circ} \mathrm{C}\right),(\mathrm{c}, \mathrm{h}) 295 \mathrm{~K}$ $\left(22^{\circ} \mathrm{C}\right),(\mathrm{d}, \mathrm{i}) 473 \mathrm{~K}\left(200^{\circ} \mathrm{C}\right),(\mathrm{e}, \mathrm{j}) 573 \mathrm{~K}\left(300^{\circ} \mathrm{C}\right)$, highlighting the temperature effect on fracture surface on both HIP and forged specimens.

therefore the volume fraction, of pores has a direct effect on the impact toughness of the material.

\section{DISCUSSIONS}

HIP'd specimens exhibited a significant area fraction of pores in the as-polished microstructure, the quantity of which has been shown to be directly proportional to the concentration of oxygen remaining in the bulk material. It has been shown that the pores are an indirect result of a high volume fraction of nonmetallic oxide inclusions, which on their removal from the austenite matrix during metallographic surface preparation leave a hole behind, rather than the result of internal porosity caused by the HIP procedure; this is in agreement with Godec, ${ }^{[19]}$ who found similar microstructural features in HIP'd 316L. The steady reduction in impact toughness with decreasing temperature is attributed to martensite formation, the amount of which is inversely proportional to the test temperature. ${ }^{[14]}$ However, the delta in impact toughness between HIP'd and forged variants of 316L stainless steel is unaffected by temperature, with HIP'd $316 \mathrm{~L}$ steel exhibiting consistently lower impact toughness at and below ambient temperature testing. From ambient to elevated temperatures however, the mechanical behavior of the two types of material becomes more comparable when the oxygen content in the HIP steel is no higher than $100 \mathrm{ppm}$. Since ductile fracture occurs via the initiation, growth, and coalescence of microvoids in a plastically deforming matrix, ${ }^{[20]}$ the presence of a significant volume fraction of nonmetallic oxide inclusions facilitate the ductile failure mechanism since they act as microvoid initiation sites ahead of the crack propagation in the austenite matrix. The greater volume fraction of inclusions results in a greater volume fraction of microvoid sites. This has the effect of reducing the energy required for ductile failure, and explains why at ambient temperature and below the Charpy impact toughness is dependent on the concentration of oxygen.

At elevated temperatures, the effect becomes less significant and the HIP'd and forged data begin to converge. This is because specimens become so ductile that fracture only occurs on a small scale; specimens tested at high temperature were able to exit the $40 \mathrm{~mm}$ spacing between the Charpy anvils through sufficient reduction in span as a result of extensive plastic deformation rather than fracture, and only shallow ductile crack growth was visible in the specimens failed at elevated temperatures. This was observed for both HIP'd and forged specimens (Figure 4). Although the effects of oxygen on ductile fracture can be rationalized in terms of void initiation sites, it is currently unclear why the highest oxygen concentration (190 ppm) exhibited a reducing effect on the general yielding of the Charpy specimens.

It has been shown that the area fraction (the mean size remains relatively unaffected) of visible microstructural pores produced by dislodged inclusions can be directly related to the total concentration of oxygen remaining in the austenite matrix post-HIP. It is also shown that the concentration of oxygen is inversely proportional to the measured Charpy impact toughness, specifically via the reduction in plastic deformation of the specimens; the peak force and general yield points obtained from the instrumented Charpy data are unaffected by oxygen content until concentrations are increased to nearly $200 \mathrm{ppm}$. Significantly, it is believed that through extrapolation of measured pore (previously inclusions) area fraction data, it is plausible to suggest that for HIP 

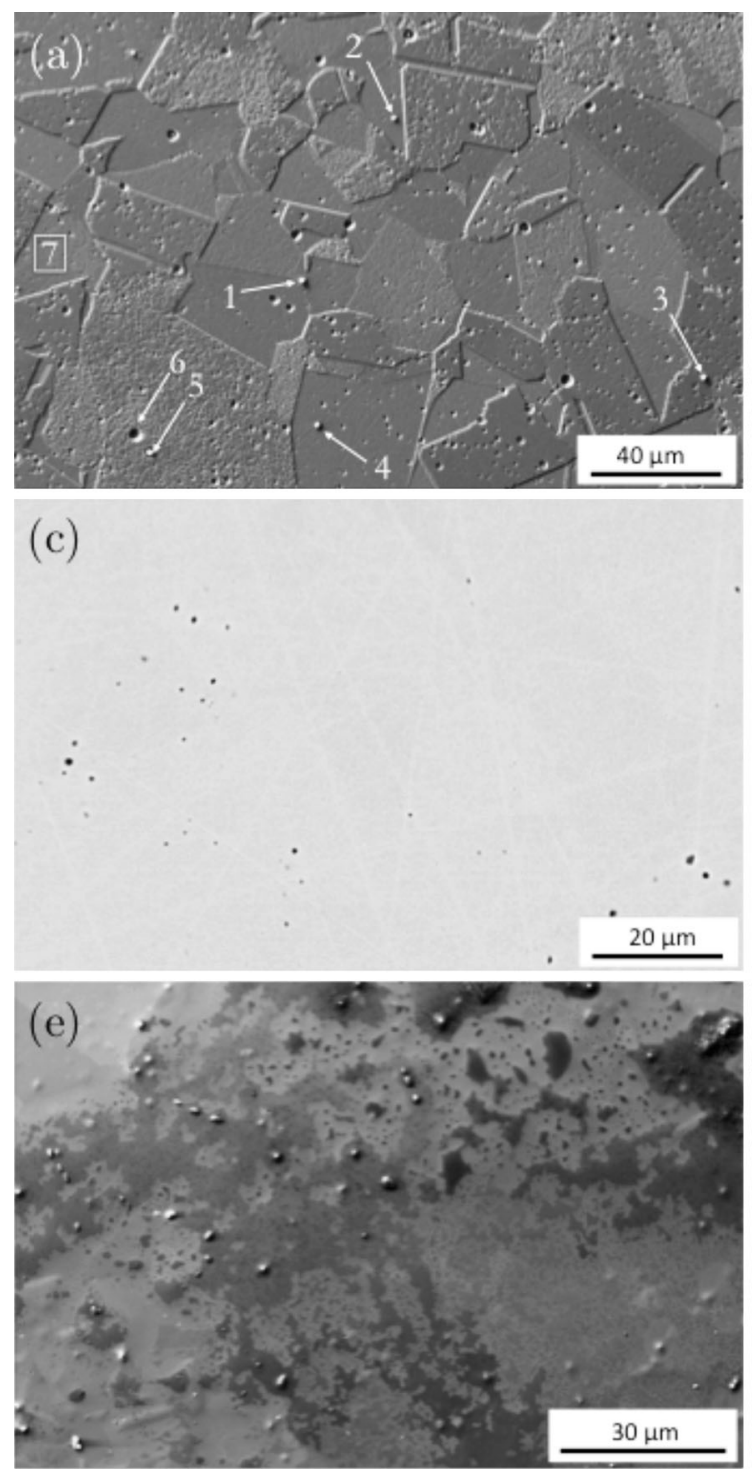

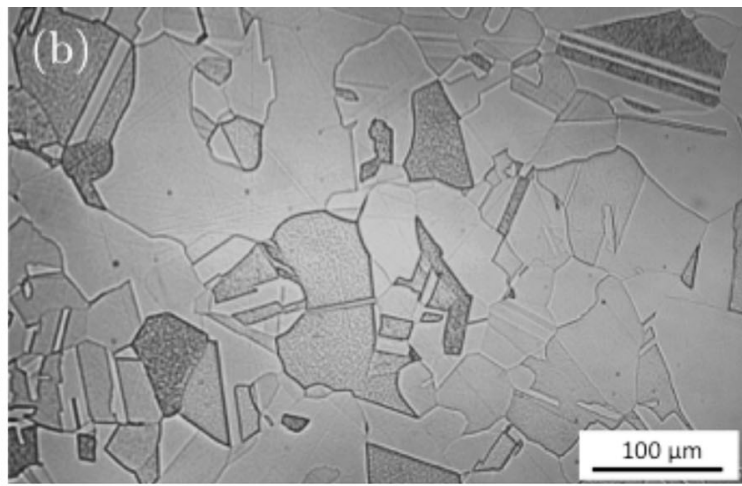

(d)

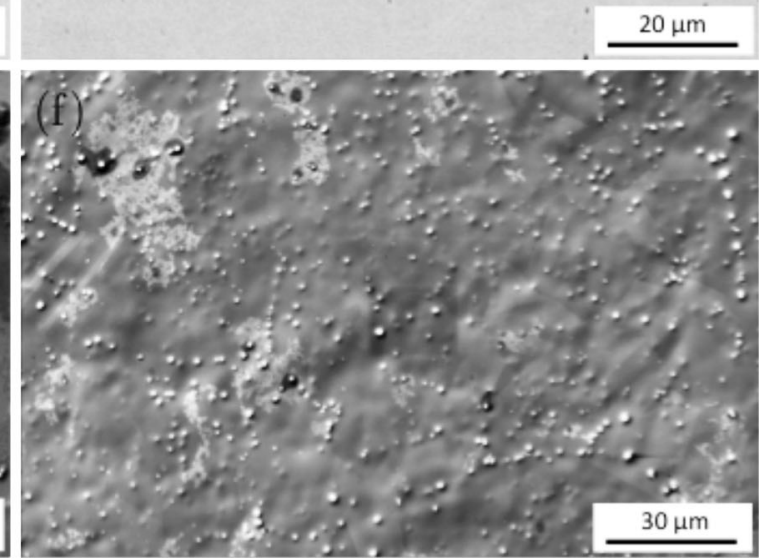

Fig. 5- (a) Secondary electron SEM image of the as-etched HIP316L showing the presence of pores and inclusions, (b) 50X optical image of the as-etched F316L, (c) as-polished HIP316L-A (100 ppm $\left.\mathrm{O}_{2}\right),(d)$ as-polished HIP316L-E (190 ppm $\left.\mathrm{O}_{2}\right)$, (e) as-electro-polished HIP316L-A $\left(100\right.$ ppm $\left.\mathrm{O}_{2}\right)$, and $(f)$ as-electro-polished HIP316L-E (190 ppm $\mathrm{O}_{2}$ ).

Table II. Elemental Analyses of Seven Selected Sites in Figure 5(a)

\begin{tabular}{lrrrrrrr}
\hline Weight Percent & 1 & 2 & 3 & 4 & 5 & 6 \\
\hline $\mathrm{O}$ & 30.5 & 34.4 & 32.5 & 40.4 & 55.0 & 0.6 \\
$\mathrm{Cr}$ & 35.3 & 36.7 & 8.6 & 21.6 & 19.3 & 17.7 & 19.4 \\
$\mathrm{Mn}$ & 18.9 & 19.7 & 15.0 & 23.7 & 19.9 & 2.0 & 2.2 \\
$\mathrm{Fe}$ & 11.9 & 7.5 & 24.2 & 5.0 & 20.3 & 62.9 & 65.6 \\
$\mathrm{Ni}$ & 2.4 & 0.8 & 4.1 & 0.4 & 4.0 & 12.8 & 0.6 \\
$\mathrm{Si}$ & 0.5 & 0.2 & 14.5 & 9.0 & 7.1 & 0.4 \\
\hline
\end{tabular}

materials to exhibit similar impact toughness properties to forged variants of $316 \mathrm{~L}$, the oxygen content must be reduced to between 30 and $60 \mathrm{ppm}$ (a conservative estimate would be ca. $30 \mathrm{ppm}$ ). This is believed to be the maximum oxygen threshold level that the austenite matrix can successfully accommodate without yielding the minimum volume fraction of oxide inclusions required to significantly reduce the impact toughness of the HIP'd material at depreciated Charpy test temperatures. 30 to $60 \mathrm{ppm}$ appears to be a sensible estimate, since the solid solubility of oxygen in pure iron is only $300 \mathrm{ppm}^{[21]}$, and since $316 \mathrm{~L}$ contains ca. $65 \mathrm{wt}$ pct $\mathrm{Fe}$, the maximum theoretical oxygen solubility in 316L's austenite phase would be ca. $195 \mathrm{ppm}$, and this is 


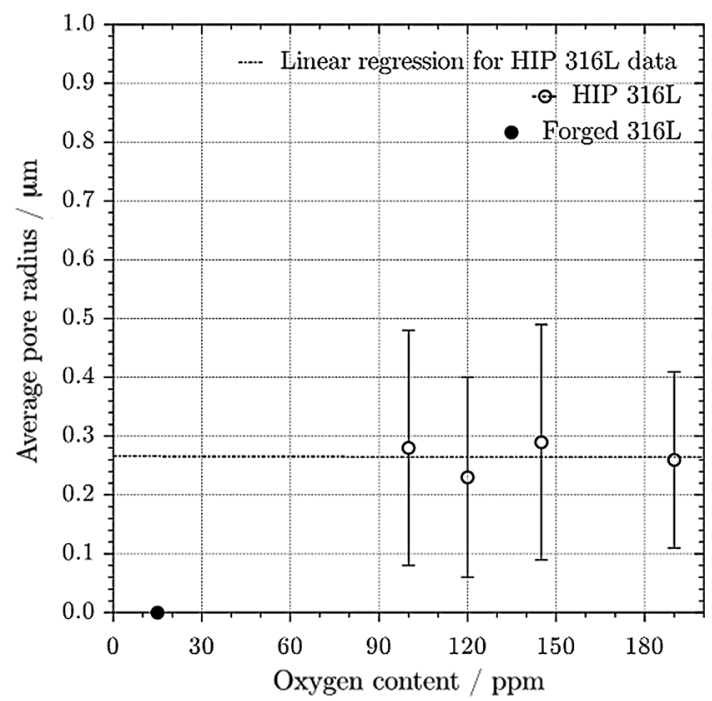

(a)

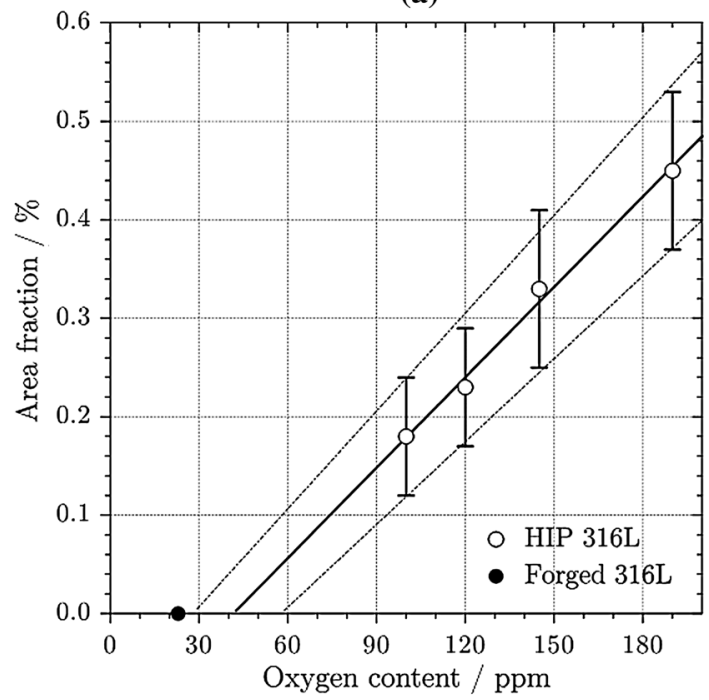

(b)

Fig. 6-Plots of $(a)$ average pore radius $(\mu \mathrm{m}) v s$ total oxygen content of 316L HIP'd material, and $(b)$ degree of microporosity, expressed as an area fraction percentage, $v s$ the total oxygen content of HIP'd 316L.

without considering all the alloying elements' greater affinity for oxygen which would further reduce the solubility.

This suggested mechanism is similar to Liao and coworkers $^{[7]}$ who attribute the decrease in impact toughness of magnesium alloys with increasing oxygen concentrations to the presence of brittle magnesium oxides and magnesium hydroxide inclusions, which act by decreasing the degree of plasticity on fracture. Similarly, Surian et al. ${ }^{[22]}$ attribute the same impact toughness/oxygen relationship in 3 pct Ni weld steel to the presence of nonmetallic inclusions, showing that higher oxygen concentrations in the weld metal yield nonmetallic inclusions of significantly larger size.

Despite the clear detrimental effects of oxygen involvement on Charpy impact toughness, the lowest impact toughness recorded for HIP $316 \mathrm{~L}$ [190 ppm $\mathrm{O}_{2}$

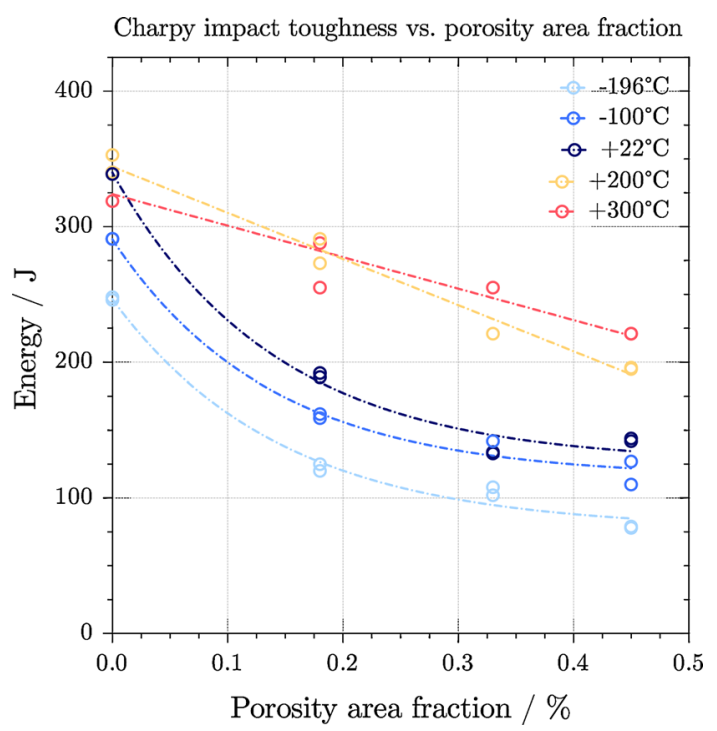

Fig. 7-Plot showing the effect of porosity area fraction on Charpy impact toughness, at five different test temperatures.

and fractured at $77 \mathrm{~K}\left(-196^{\circ} \mathrm{C}\right)$ ] was $78 \mathrm{~J}$ and remains above code standards of $20 \mathrm{~J}$ for boiler and pressure vessel applications at low-temperature service. ${ }^{[23,24]}$ However, this $78 \mathrm{~J}$ is substantially lower than that of F316L ( ca. $250 \mathrm{~J}$ ), and is relatively close to the quoted recommended minimum standard. This highlights the importance of reducing the concentration of oxygen and establishing a maximum oxygen content threshold in HIP manufacture. It should be noted that although minimum Charpy energies were recorded at $77 \mathrm{~K}$ $\left(-196{ }^{\circ} \mathrm{C}\right)$, temperatures that are not normally associated with nuclear reactors, there is certainly an observed temperature shift between HIP and forged variants of 316L. Irradiation hardening of 316L austenitic stainless steel is well known, ${ }^{[25]}$ and it is unclear at this stage how large the effects of neutron irradiation would be on these shifted impact toughness data. Finally, at elevated temperature testing $573 \mathrm{~K}\left(300^{\circ} \mathrm{C}\right)$ the mechanical properties of HIP and forged materials become comparable, the temperature at which components would be required to operate at in a reactor.

\section{CONCLUSIONS}

It has been shown that oxygen involvement in the HIP process results in the presence of visible microporosity in the microstructure of the HIP'd materials, and that there is a linear relationship between oxygen content and area fraction of the resulting microporosity. The observed microporosity has been shown to be the result of nonmetallic oxide inclusions, which are dislodged during mechanical polishing and leave behind a pore on their removal. It was assumed that the number of pores $\equiv$ number of inclusions, and are able to relate the total area fraction of inclusions to the total oxygen content in the HIP specimens. The average pore size appears to be unaffected by increasing concentrations of oxygen involvement during HIP. However, there is a relatively 
diverse range of pore sizes present in the microstructure ranging from less than $0.1 \mu \mathrm{m}$ to greater than $0.5 \mu \mathrm{m}$. It has been shown that oxygen involvement, porosity area fraction, and Charpy impact toughness of Type 316L stainless steels are all directly linked to one another, and in order for HIP'd 316L to exhibit material properties similar to those set by equivalent forged $316 \mathrm{~L}$, it is essential to be able to specify a maximum concentration of oxygen which should remain in the HIP'd material; the present paper indicates that this should be between 30 and $60 \mathrm{ppm}$, in order to prevent the manifestation of a substantial volume fraction of nonmetallic oxide inclusions.

\section{OPEN ACCESS}

This article is distributed under the terms of the Creative Commons Attribution 4.0 International License (http://creativecommons.org/licenses/by/4.0/), which permits unrestricted use, distribution, and reproduction in any medium, provided you give appropriate credit to the original author(s) and the source, provide a link to the Creative Commons license, and indicate if changes were made.

\section{REFERENCES}

1. V. Viswanathan, T. Laha, K. Balani, A. Agarwal, and S. Seal: Mater. Sci. Eng. R Rep., 2006, vol. 54, pp. 121-285.

2. Y.C. Jeon and K.T. Kim: Int. J. Mech. Sci., 1999, vol. 41, pp. 815-30.

3. C. Barre: Adv. Mater. Process., 1999, vol. 155, pp. 47-8.

4. H.V. Atkinson and S. Davies: Metall. Mater. Trans. A Phys. Metall. Mater. Sci., 2000, vol. 31, pp. 2981-3000.
5. H.T. Larker and R. Lundberg: J. Eur. Ceram. Soc., 1999, vol. 19, pp. 2367-73.

6. G.A. Rao and M. Kumar: Mater. Sci. Technol., 1997, vol. 13, pp. 1027-31.

7. J. Liao, M. Hotta, and A. Koshi: Mater. Lett., 2011, vol. 65, pp. 2995-99.

8. A. Lind, J. Sundström, and A. Peacock: Fusion Eng. Des., 2005, vols. 75-79, pp. 979-83.

9. Z. Oksiuta, E. Boehm-Courjault, and N. Baluc: J. Mater. Sci., 2010, vol. 45, pp. 3921-30.

10. Y. Sato, T. Maie, and T. Kuwana: In Proceedings of the International Conference on Offshore Mechanics and Arctic Engineering-OMAE. (1995), pp 485-90.

11. O. Kamiya, H. Fujita, T. Enjo, and Y. Kikuchi: Q. J. Jpn. Weld. Soc., 1985, vol. 3, pp. 574-81.

12. L. Arnberg, and A. Karlsson, International Journal of Powder Metallurgy (Princeton, New Jersey). 1988, vol. 24, pp. 107-12.

13. M.A. Ashworth, J.C. Bryar, M.H. Jacobs, and S. Davies: Powder Metall., 1999, vol. 42, pp. 243-49.

14. A.J. Cooper, N.I. Cooper, A. Bell, J. Dhers, and A.H. Sherry: Metall. Mater. Trans. A, 2015, vol. 46A, pp. 5126-38.

15. ASTM E112-96: Standard Test Methods for Determining Average Grain Size, ASTM International, West Conshohocken, PA, 1996.

16. ASTM A370-14: Standard Test Methods and Definitions for Mechanical Testing of Steel Products, ASTM International, West Conshohocken, PA, 2014.

17. ASTM E3-01: Standard Practice for Preparation of Metallographic Specimens, ASTM International, West Conshohocken, PA, 2001.

18. Private correspondence with Electric Power Research Institute USA.

19. M. Godec: Mater. Tehnol., 2011, vol. 45, pp. 85-90.

20. P.F. Thomason: Ductile Fracture of Metals, Pergamon Press, Oxford, 1990.

21. B.P. Bhardwaj: Steel and Iron Handbook, NIIR project consultancy services, New Delhi, 2014.

22. E. S. Surian, J. L. Trotti, and T. Boniszewski, Weld. J. 1992, vol. 71.

23. S.F. Kane, A.L. Farland, T.A. Siewert, and C.N. McCowan: Weld. J., 1999, vol. 78 (8), pp. 292-300.

24. ASTM A312/A312M: Standard Specification for Seamless and Welded Austenitic Stainless Steel Pipes, ASTM International, West Conshohocken, PA, 2006.

25. S.A. Maloy, M.R. James, G. Willcutt, W.F. Sommer, M. Sokolov, L.L. Snead, M.L. Hamilton, and F. Garner: J. Nucl. Mater., 2001, vol. 296, pp. 119-28. 